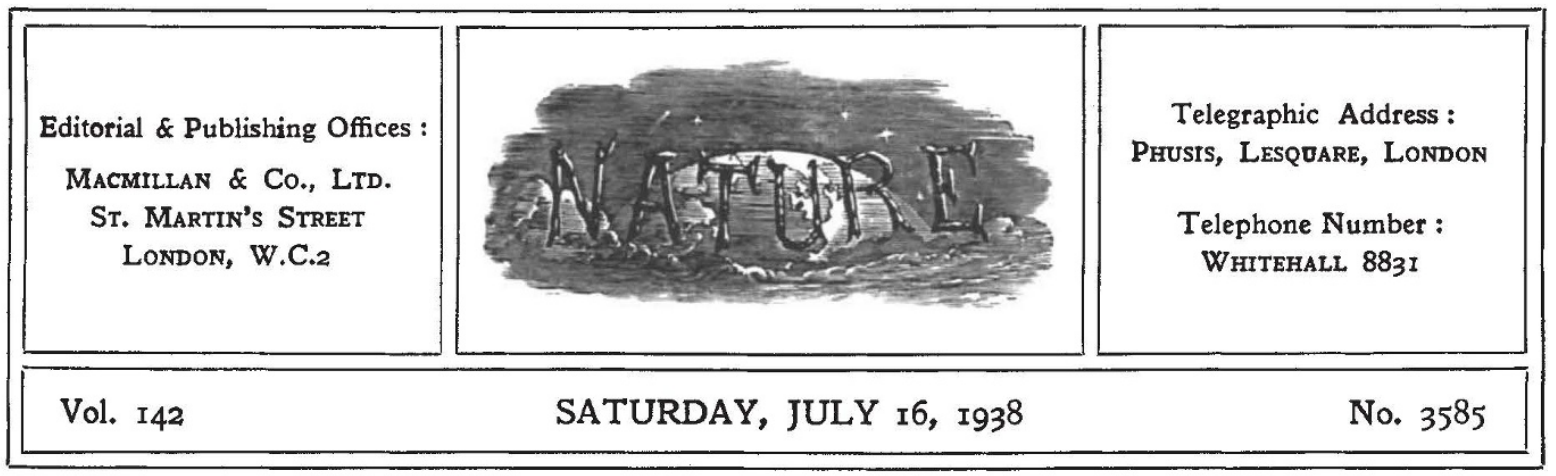

\title{
Science and Government
}

A LECTURE entitled "Science and Government", recently delivered to the Royal Philosophical Society of Glasgow by Prof. J. Graham Kerr, raises questions of the widest concern. Its theme is the utilization of science in the interests of the community and the inculcation of scientific methods of thought into governancematters outside the sphere of party politics. Prof. Graham Kerr is a believer in democracy and prefers our bureaucratic system to that of totalitarian States; the former is slow in action but flexible, while the latter, though more speedy in action, has a certain rigidity, and its dependence on the ability and principles of the individual renders it liable to a sudden collapse. $\mathrm{He}$ compares the bureaucratic machine to an organism. Its increase in size contains its own elements of danger in the development of a longer and longer chain of organization, which is liable to have weak links and thus to break down under strain.

It is unquestioned that the organized modern State depends on the successful applications of science, alike to the feeding, motility, health and recreation of the whole population, as well as in securing the safety of the community from foreign aggression. The development and efficiency of services in these matters are the sole concerns of several ministries. The business of their executive officers is, for the most part, the application of regulations in their different spheres, but secondarily they have to advise the ministers responsible to Parliament. As the higher departmental staffs consist of individuals generally chosen for ability by examinations in which science, being unprofitable, is a subordinate subject, ministers can scarcely rely upon their advice in major concerns; if capable of understanding, they have not the time- perchance, the inclination-to keep abreast of the advances of science. Hence the institution of advisory committees, strongly endorsed by Prof. Graham Kerr on account of their "cold-blooded, judicial consideration" of questions placed before them.

The personnel of these committees, having been properly selected, must subject the ministers to no "fussy interference", while, above all, a ministry must in its turn try neither to persuade nor to bring pressure by raising purely administrative or political difficulties. As a general principle, it is suggested that every administrative ministry, civil and military, should have its own advisory committee, and examples of the success of these committees are given. In all cases where a ministry has its own scientific department, it should help its members to discuss their scientific problems with colleagues whose activities are more concerned with the fundamentals of science. In the modern civilized State, however, all these matters depend ultimately for their success on the general educational system, which is considered by Prof. Graham Kerr to demand a thorough overhaul as a matter of national concern.

Considering the topic 'science and government' more widely, we regret that Prof. Graham Kerr did not let his thoughts wander to the Empire. The Dominions have made considerable advances in education by the evolution of new technique and the development of almost new subjects-and in most of their interests they have independent experts upon whom they can call for advice. The Colonies have practically no experts apart from those commercially and personally concerned. Colonies represent earlier stages in the evolution of civilized States and independent democracies 
than do Dominions. Their environmental conditions are obviously immature. Health is allimportant; food has to be produced, perhaps new foods introduced; transport should be easy; luxuries from abroad must be balanced by excess production culminating in exportation ; and lastly all questions concern at least two races of man in each colony. Here, as in the home State, success depends on experts, between them capable of applying each branch of science. More often than not these experts are private individuals who risk their wealth in practical business, an excellent arrangement provided that this business is kept duly subordinated to the interests of the colony.

The executive officers of a colony have to devote their energies to keep the machinery of government smoothly running and to this end have now some training enabling them to consider the interrelationships of races living together. How far are these individuals, largely chosen for their informative and cultural education, capable of dealing (for example) with food production and, perchance, the reports of specialist officers, if they themselves are ignorant of the basal methods employed in such work? Obviously governors of colonies scarcely belong to the present age, but how many of their executive officers have been trained in the methods of science? What value is placed on such knowledge in their selection? In the probationary period, before proceeding to colonies, what time is devoted to training in the scientific method, if the individual is chosen for other sides of learning? In other words, have the methods in the governance of the Colonies kept pace with the scientific evolution of the last decades? The Colonial Office alone has the information necessary for reply. In democracy, colonies must be held by the consent and goodwill of the governed, and the Empire demands an efficiency of management leading through prosperity to a permanency of union.

Lastly, from our point of view, the payment and pension problem has long been a matter of concern, the conditions in the scientific services being inferior to those in the administrative. In a statement to Parliament*, the Colonial Office appreciates the necessity of a "Standardisation of Conditions", which, since "a uniform pension rate has been laid down as suitable for officers of the unified Services", can only mean a gradual rectification of a grievance of scientific workers. This is a necessary step to secure the best recruits for the scientific services, the training for which is long and intensive and in which only men of high ability are required. The Colonial Office thereby attains a liberty of action which previously it could not exercise. No longer need it transfer an officer who has made an intensive study of the scientific problems of one colony to a post in another, thus promoting him while rendering his study nugatory. If the Colonial Office requires, he can now be called upon without injustice to identify himself with the particular colony in which his success and perhaps affection lie. The old system of promotion, solely by transference, was often unsuited to the scientific services and made permanency in any colony a sign of ineffectiveness.

* The Colonial Empire in 1937-38: Statement to accompany the Estimates for Colonial and Middle Eastern Services, 1938. (Cmd. 5760.) Pp. 79. (London: H.M.S.O.) 18. $3 d$. net.

\section{Principles of Factorial Experiments}

The Design and Analysis of Factorial Experiments

By F. Yates. (Imperial Bureau of Soil Science. Technical Communication No. 35.) Pp. 96. (Harpenden: Imperial Bureau of Soil Science, 1937.) $5 s$.

THE publications of the various Imperial 1 Bureaux are necessarily of very unequal scientific value, and naturally also, appeal to very different bodies of scientific workers. Their format and presentation are not such as to excite an expectation of material of wide interest. Thus, the reader who encounters first in large letters
"Imperial Bureau of Soil Science", and then the somewhat repellent caption "Technical Communication No. 35", is not well prepared for the exceptional interest of the material presented by Mr. Yates in the monograph under notice. It should, therefore, be stated at once that this particular publication has been awaited eagerly by experimenters in all parts of the world, and that in providing, not only a much needed compendium of well-established designs, but also the practical solutions of a number of the problems outstanding, it will more than justify the expectations that have been formed.

For at least a century, experimenters have felt 